\title{
Nitric Oxide Inhibits Execution of Apoptosis at Two Distinct ATP-Dependent Steps Upstream and Downstream of Mitochondrial Cytochrome c Release
}

\author{
Marcel Leist, Barbara Single, Heike Naumann, Eugenio Fava, \\ Bernadett Simon, Simone Kïhnle, and Pierluigi Nicotera ${ }^{1}$ \\ Faculty of Biology, Department of Molecular Toxicology, University of Konstanz, D-78457 Konstanz, Germany
}

The endogenous mediator nitric oxide (NO) blocked apoptosis of Jurkat cells elicited by staurosporine, anti-CD95 or chemotherapeutics, and switched death to necrosis. The switch in the mode of cell death was dependent on the ATP loss elicited by NO. This affected two distinct steps of the apoptotic cascade. First, the release of cytochrome $c$ from mitochondria was delayed by NO. Second, processing of procaspases $-3 / 7$ to the active proteases was prevented even after cytochrome c had been re. leased. Thus, NO interferes with execution steps of apoptosis both upstream and downstream of cytochrome $c$ release. (1) 1999 Academic Press

Key Words: ATP; caspase; nitric oxide; apoptosis; necrosis; cytochrome $c$.

Apoptosis is an evolutionary conserved form of cell death, that is essential for most multicellular organisms to remove unwanted cells without disrupting tissue organization, provoking scarring, and triggering inflammation [1,2]. Pharmacological intervention with caspase inhibitors [3], an increase of the intensity of the death-inducing stimulus [4], or depletion of intracellular ATP $[5,6]$ are known to preclude the execution of apoptosis. In many of the above cases, cell demise is not entirely prevented, but rather switched to necrosis, a mode of death often involving inflammation, scarring and prevention of tissue reconstitution [1].

The endogenous factors which decide on the switching of apoptosis to necrosis under pathological conditions are still unknown. One potential candidate is nitric oxide (NO) which is produced in high concentra-

'To whom correspondence should be addressed at Faculty of Biology, University of Konstanz, Box X911, D-78457 Konstanz, Germany. Fax: +49-7531-884033. E-mail: Pierluigi.Nicotera@unikonstanz.de. tions at inflammatory sites [7,8], and which is known to block apoptosis in many experimental paradigms [9-12]. Prevention of apoptosis by NO may involve different mechanisms. For instance, NO may increase intracellular cyclic guanosine monophosphate [12-14], deplete ATP by inhibiting the mitochondrial respiratory chain [15-18], or it may inactivate caspases $[13,19,20]$, key proteases involved in the execution of apoptosis. Moreover, it has been already proposed that prevention of apoptosis by NO may only be ephemeral in some cell types [21], and may eventually result in necrosis.

This study was undertaken to investigate whether, and under which conditions, NO can switch apoptosis to necrosis. To examine whether NO changed the mode of cell death because of its ability to deplete ATP, we used cells energized exclusively by the mitochondrial energy substrate pyruvate, as compared to cells having access to substrates of glycolysis. We then examined which steps of the apoptotic cascade were inhibited by NO or by the resulting ATP depletion.

\section{MATERIALS AND METHODS}

Materials. SYTOX, ethidium homodimer-1 (EH-1), and H-33342 were obtained from Molecular Probes (Eugene, OR, USA). S-nitrosoglutathione (GSNO) and S-nitroso- $\mathrm{N}$-acetyl-penicillamine (SNAP) were synthesized and quantitated as described before [22]. The caspase substrate DEVD-aminotrifuoromethylcoumarine (-afc) was obtained from Biomol (Hamburg, Germany). All other reagents not further specified were from Sigma (Deisenhofen, Germany).

Cell cultures. Jurkat cells were grown in RPMI 1640 medium supplemented with $10 \%$ fetal calf serum. Before the experiments, cells were washed and resuspended in serum- and glucose-free medium containing $2 \mathrm{mM}$ pyruvate, which was named $P N G$ (Pyruvate No Glucose) medium. The standard experimental protocol involved adaptation of the cells to this medium for $60 \mathrm{~min}$, subsequent exposure to oligomycin or NO-donors for $45 \mathrm{~min}$, and then challenge with staurosporine (STS), an agonist monoclonal antibody against CD95 (clone CH-11, Immunotech, Marseille, France), or other apoptotic 
stimuli. To restore ATP generation, PNG medium was supplemened with glucose $(10 \mathrm{mM})$, where indicated.

Viability assays. To distinguish morphologically apoptotic, necrotic and living cells, cultures were stained with a mixture of the membrane permeant chromatin dye $\mathrm{H}-33342(500 \mathrm{ng} / \mathrm{ml}$; staining all nuclei) and the membrane impermeant dye SYTOX $(500 \mathrm{nM})(5,22)$. The percentages of necrotic (SYTOX-positive; non-condensed nuclei) and apoptotic cells (intact plasma membrane; characteristically condensed or fragmented nuclei) were determined scoring 300-500 cells in 3-6 different fields using a Leica microscope and lens providing $400 \mathrm{x}$ final magnification. Histone-containing oligonucleosomal DNA-fragments were quantitated by ELISA (Boehringer Mannheim, Germany) [5] by using a lysate obtained from about 500 cells. Frag. mentation data are given in relation to untreated control cells. ATP was determined luminometrically as described before [5].

Phosphatidylserine translocation. Surface phosphatidylserine expression was analysed by annexin V-staining and confocal microscopy (TCS-4D UVNIS confocal scanning system; Leica AG, Benzheim, and Leica Lasertechnik, Heidelberg, Germany), as described previously $[5,23]$. Jurkat cells were immobilized on glass bottomed cell culture dishes, coated with $100 \mu \mathrm{g} / \mathrm{ml}$ polylysine and stained with $\mathrm{H}-33342, \mathrm{EH}-1$, and fuorescein-conjugated annexin $\mathrm{V}$ (Boehringer Mannheim, Mannheim, Germany). In the experiments shown, necrotic cells (EH-1 positive) were excluded from scoring and were always $\leqslant 10 \%$.

Electrophoretic assays/Western blots, Cytoplasmic cytochrome c content and caspase-mediated proteolysis were analysed by immunoblot. For caspase specific proteolysis, Jurkat cells were lysed in a RIPA-buffer ( $150 \mathrm{mM} \mathrm{NaCl}, 50 \mathrm{mM}$ Tris, $1 \% \mathrm{NP}-40,0.25 \%$ sodium deoxycholate, $1 \mathrm{mM}$ EGTA), which was supplemented with inhibitors of other classes of proteases $(1 \mathrm{mM}$ phenylmethylsulfonyl fluoride (PMSF), $1 \mathrm{mM}$ benzamidine, $1 \mathrm{mM}$ iodoacetate, $1 \mathrm{mM}$ iodoacctamide, $40 \mu \mathrm{M}$ leupeptin, $10 \mu \mathrm{g} / \mathrm{ml}$ antipain, $5 \mu \mathrm{g} / \mathrm{ml}$ pepstatin). Before lysis, cultures were stained with $0.5 \mu \mathrm{M}$ SYTOX to control the percentage of cells with intact membranes, which was over $95 \%$ for all samples analyzed. For cytochrome c, we used cell fractions obtained after digitonin lysis [24]: Jurkat cells $\left(4 \times 10^{6}\right)$ were harvested at $700 \mathrm{xg}$ for $3 \mathrm{~min}$, and resuspended in $250 \mu$ l phosphate buffered saline ( $\left.2 \mathrm{mM} \mathrm{NaH}_{2} \mathrm{PO}_{4}, 16 \mathrm{mM} \mathrm{Na}_{2} \mathrm{HPO}_{4}, 150 \mathrm{mM} \mathrm{NaCl}(\mathrm{PBS})\right)$ at room temperature. Cell were lysed by quickly adding $250 \mu \mathrm{l}$ of digitonin in $500 \mathrm{mM}$ sucrose $\left(9.4 \mu \mathrm{g}\right.$ digitonin $/ 10^{6}$ cells) under vigorous vortexing. After $30 \mathrm{~s}$ at room temperature, organelles and cell debris were separated from the lysate by centrifugation at $14,000 \mathrm{x}$ $\mathrm{g}$ for $60 \mathrm{~s}$, at $4^{\circ} \mathrm{C}$. The resulting supernatant was used for Western blot analysis. Samples were separated by SDS-polyacrylamide gel electrophoresis, and electroblotted onto nitrocellulose membranes (Hybond ECL, Amersham-Buchler Corp., Braunschweig, Germany). Protein content was routinely controlled by staining of blot membranes with Ponceau Red and by re-developing the membranes with an anti-actin antibody (1:100,000 Chemicon Inc., Temecula, CA, clone $\mathrm{C} 4)$. The membranes were blocked, and incubated with the primary antibodies $(1.5 \mu \mathrm{g} / \mathrm{ml}$, clone $7 \mathrm{H} 8.2 \mathrm{C} 12$, Pharmingen, Hamburg, Germany) against cytochrome c; clone C2-10 (1:1000, Pharmingen) against PARP; anti-procaspase-3 (1:1000, Signal Transduction Laboratories, Lexington, USA or Upstate Biotech \# 06-735); anti-caspase-7 (1:1000; was generously provided by Dr. G. Cohen, MRC Toxicology Unit Leicester, U.K. [25]), anti-caspase-8 (1:10; was generously provided by Dr. K. Schulze-Osthoff, Tübingen, Germany, [26]). Where indicated, membranes were probed and developed against PARP and procaspase-3 simultaneously. All blots were developed with a polyclonal IgG-horseradish peroxidase (1:1000, Pharmingen) followed by enhanced chemiluminescence detection (ECL, Amersham).

Caspase and adenylate kinase activity. Caspase activity (DEVDafc cleavage) was assayed essentially as described before $[27,28]$. Jurkat cells $\left(1.5 \times 10^{5}\right)$ were lysed in HEPES $(25 \mathrm{mM}), \mathrm{MgCl}_{2}(5$

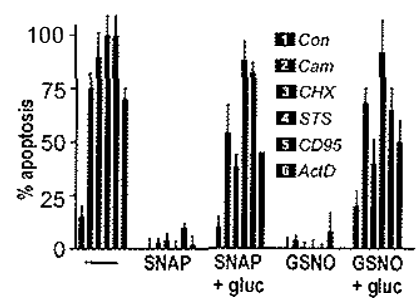

FIG. 1. Inhibition of apoptosis by $\mathrm{NO}$ is reversed by glucose. Jurkat cells were incubated in PNG medium or medium supplemented with $10 \mathrm{mM}$ glucose. NO donors $(0.4 \mathrm{mM}$ GSNO or $0.6 \mathrm{mM}$ SNAP) were added $60 \mathrm{~min}$ after plating. Exposure to toxins (1, control (con); 2, camptothecine (10 $\mu \mathrm{M}, \mathrm{CAM}) ; 3$, cycloheximide (100 $\mu \mathrm{M}, \mathrm{CHX}) ; 4$, staurosporine (1 $\mu \mathrm{M}$; STS); 5 , CH-11 (100 ng/ml; CD95); 6, actinomycin D (2 $\mu \mathrm{g} / \mathrm{ml}$, ActD)) started after $105 \mathrm{~min}$. Apoptosis was determined after $11 \mathrm{~h}$ by counting the percentage of cells with condensed chromatin

$\mathrm{mM})$, EGTA (1 mM), Triton X-100 (0.5\%), leupeptin (1 $\mu \mathrm{g} / \mathrm{ml})$, pepstatin $(1 \mu \mathrm{g} / \mathrm{ml})$, aprotinin $(1 \mu \mathrm{g} / \mathrm{ml}), \operatorname{AEBSF}(1 \mathrm{mM}), \mathrm{pH} 7.5$. The fuorimetric assay was performed in microtiter plates with a substrate concentration of $40 \mu \mathrm{M}$ and a total protein amount of $5 \mu \mathrm{g}$. Cleavage was followed in reaction buffer $(50 \mathrm{mM}$ HEPES, $10 \mathrm{mM}$ dithiothreitol (DTT), $1 \%$ sucrose, $0.1 \%$ CHAPS) over a period of 30 min at $37^{\circ} \mathrm{C}$ with $\lambda_{\mathrm{ex}}=390 \mathrm{~nm}$ and $\lambda_{\text {ext }}=505 \mathrm{~nm}$. The activity was calibrated with afc-standard solutions. Adenylate kinase was determined spectrophotometrically as described [24]

\section{RESULTS}

\section{Apoptosis of Jurkat Cells Is Prevented by NO and Restored by Glucose}

In all experiments, Jurkat cells were incubated in PNG-medium with or without glucose supplementation. In pure PNG medium, intracellular ATP is generated by the mitochondrial ATP synthase mainly $[5,6]$. Under these conditions, the intracellular ATP level is normal as long as mitochondria remain fully functional. When mitochondrial respiration is fully inhibited, ATP levels can be maintained at a maximum by supplementing glucose as a substrate for glycolytic ATP generation [5,6]. Five different apoptotic stimuli (actinomycin D, cycloheximide, camptothecine, staurosporine (STS), anti-CD95 (CH-11)), elicited apoptosis in more than $70 \%$ of the cells in either of the two media. The two NO-donors S-nitroso- $\mathrm{N}$-acetylpenicillamine (SNAP) and S-nitrosoglutathione (GSNO) abolished apoptosis (Fig. 1). The inhibition was almost completely reversed by addition of glucose to the PNG medium, similar to the effect of the ATPase inhibitor oligomycin described before [5].

\section{Long-Term Exposure to NO Triggers Apoptosis or Necrosis Depending on the Glucose Content in the Medium}

Long-term $(24 \mathrm{~h})$ exposure of Jurkat cells to NO donors in the concentration range used here causes cell 


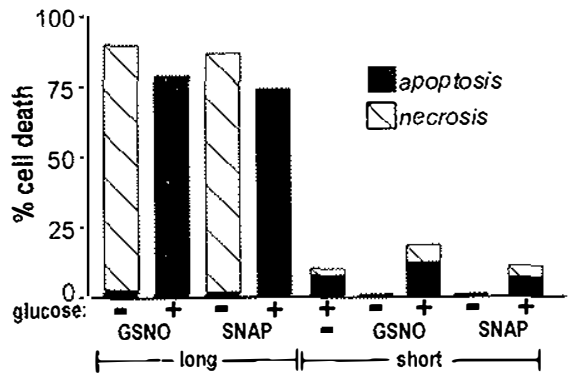

FIG. 2. Apoptosis or necrosis induced by long-term exposure to NO. Jurkat cells were incubated in PNG medium \pm glucose with GSNO $(0.6 \mathrm{mM})$ or SNAP $(0.8 \mathrm{mM})$. In one set of cells (short), NO-donors were removed after $240 \mathrm{~min}$, and medium supplemented with glucose was added. Another set of cells was continously exposed to $\mathrm{NO}$ (long). After $24 \mathrm{~h}$, the percentage of apoptosis and necrosis was determined in all sets of cells by H-33342/SYTOX staining. Data are means \pm S.D. from three determinations obtained in separate experiments.

death. GSNO, SNAP (Fig. 2), or spermine-NO (not shown) elicited $\geq 75 \%$ apoptosis in glucose-containing medium. However, the same treatment elicited necrosis in glucose-free PNG medium. Thus, it is conceivable that high and sustained release/production of NO may cause cell death by necrosis under certain metabolic situations in vivo.

In contrast, incubation of cells with NO-donors for a limited time (i.e. between 4 and $11 \mathrm{~h}$ ) followed by continued culture for 20 hours, did not result in significant cell death unless additional stimuli were added (Figs. 1 and 2).

\section{ATP Depletion and NO Donors Delay the Release of Mitochondrial Proteins into the Cytosol}

Jurkat cells incubated with staurosporine undergo a classical apoptotic process in PNG medium regardless of the presence or absence of glucose. If GSNO (or SNAP, not shown) was added, ATP was depleted in PNG medium, but not in medium supplemented with glucose (Fig. 3A). Accordingly, STS plus GSNO triggered necrosis in PNG medium and apoptosis in medium supplemented with glucose (Fig. 3A) similar to other ATP-depleting agents [5].

A rather common step in many apoptotic cascades is the release of proteins, such as cytochrome c, from the mitochondrial intermembrane space into the cytosol [29]. Cells undergoing apoptosis also release the mitochondrial enzyme adenylate kinase (ADK) in addition to cytochrome c [24]. In PNG-medium, NO-donors significantly delayed the release of ADK into the cytosol, whereas NO did not inhibit ADK-release in the presence of glucose (Fig. 3A). A similar NO-dependent delay was observed, when we measured the release of mitochondrial cytochrome c into the cytosol of STSstimulated Jurkat cells in PNG medium (Fig. 3B).
In the next set of experiments, we examined, whether ATP-depletion caused by oligomycin would produce similar effects. Also here, the release of both cytochrome $c$ and ADK was clearly delayed (Fig. 3C).

If cell death was triggered by stimulating CD95 with the monoclonal antibody $\mathrm{CH}-11, \mathrm{NO}$ again switched the mode of death from apoptosis to necrosis in ATPdepleted cells. In parallel, the release of ADK and of cytochrome $\mathrm{c}$ was delayed (Fig. 4).

Thus, NO did not modify the execution of apoptosis in the presence of glucose, which suggests that NO itself did not inactivate STS or disable CD95 signalling, but rather acted indirectly via ATP depletion.

\section{Necrotic Cytochrome c Release Does Not Cause \\ Phosphatidylserine Translocation and \\ Nuclear Condensation}

Since NO or other ATP-depleting conditions delayed, but did not prevent cytochrome c release, we examined other characteristic features of the apoptotic process. NO donors in PNG medium completely inhibited (rather than delaying) the translocation of phosphatidylserine to the outer leaflet of the plasma membrane elicited by either STS (Fig. 5) or CH-11 (not shown). NO had no effect on the translocation in medium supplemented with glucose. Nuclear and plasma membrane changes seemed to be equally inhibited by NO, since the occurrence of PS translocation correlated closely with changes of the nuclear morphology as determined by imaging of individual cells (Fig. 5). NO-dependent ATP-depletion consistently prevented downstream apoptotic changes, even after the delayed release of cytochrome $\mathrm{c}$ into the cytosol. Thus, in addition to delaying release of cytochrome c, NO affected further steps of the apoptotic cascade in PNG medium.

\section{ATP Depletion Prevents Activation of Execution Caspases}

Since the onset of necrosis was considerably delayed by NO (if compared to apoptosis observed in the absence of $\mathrm{NO}$ ), we examined whether caspase activation would also be delayed or rather be entirely prevented. In PNG medium, the presence of NO completely prevented the increase in activity of DEVD-afc-cleaving caspases, normally triggered by STS (Fig. 6A). The accompanying oligonucleosomal DNA-fragmentation was prevented as well. However, caspases were strongly and rapidly activated, and DNA was fragmented in cells treated with STS plus NO, if the medium was supplemented with glucose. Similar findings were obtained with oligomycin (Fig. 6A).

In cells treated with $\mathrm{CH}-11$ plus NO in PNG medium, a small and delayed increase of DEVD-afc cleavage was observed (Fig. 6A). This may be explained by 

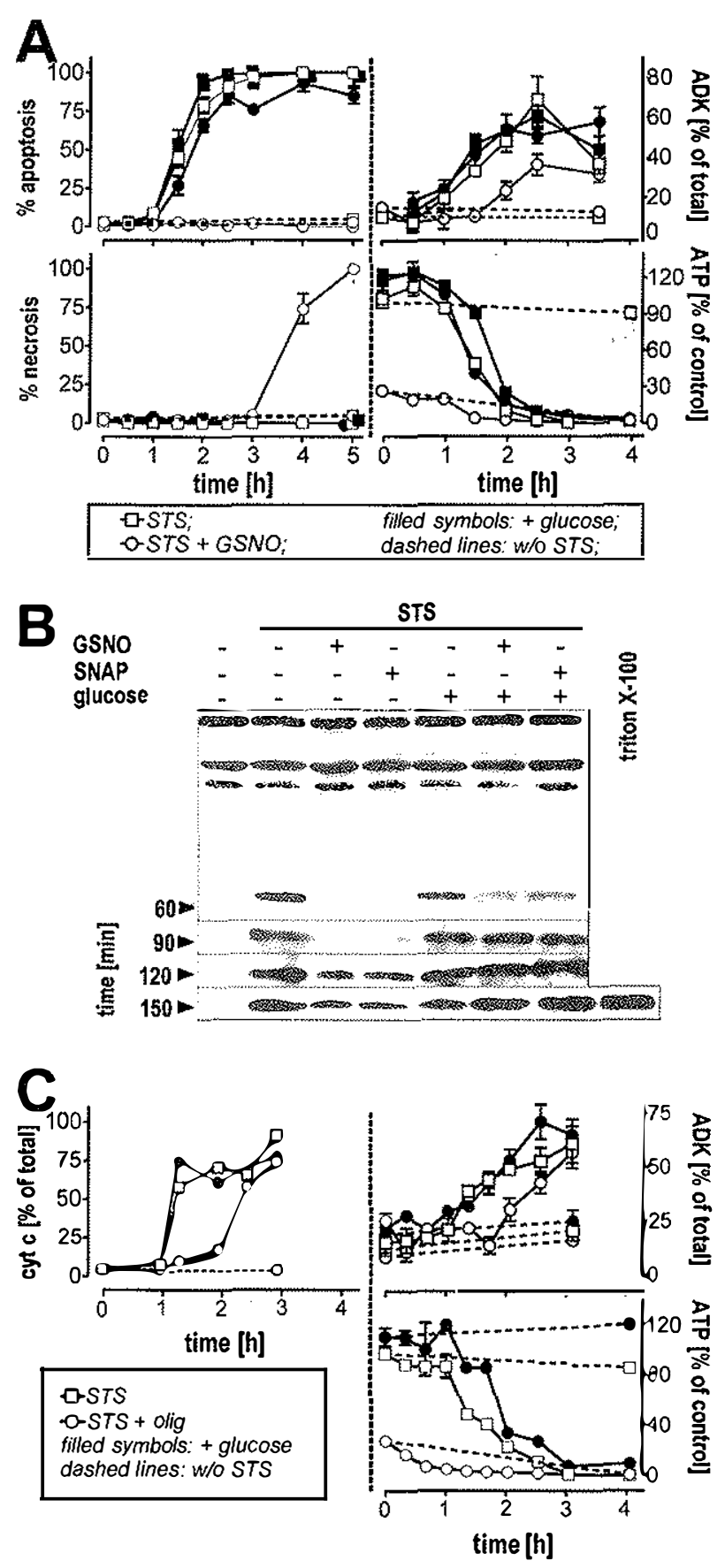

FIG. 3. Time course of apoptotic events in STS-treated cells exposed to NO or oligomycin. (A) Jurkat cells were incubated in PNG medium with (filled symbols) or without (open symbols) glucose (10 $\mathrm{mM})$. They were stimulated with STS (1 $\mu \mathrm{M}$, squares) or STS plus GSNO (0.4 mM, circles). Incubations performed with NO in PNG medium, but without STS are indicated by dashed lines. Apoptosis and necrosis were quantitated by H-33342/SYTOX staining. Adenylate kinase activity was measured spectophotometrically in cytosolic extracts. Data are given as \% of the total activity releasable by Triton $\mathrm{X}$-100. Cellular ATP content is given as \% of control cells. Data are means $+\mathrm{SD}$ from triplicate determinations. (B) Cytosolic cytochrome c (marked with arrowheads) content after incubation of Jurkat cells with combinations of glucose, NO-donors and STS for 60,
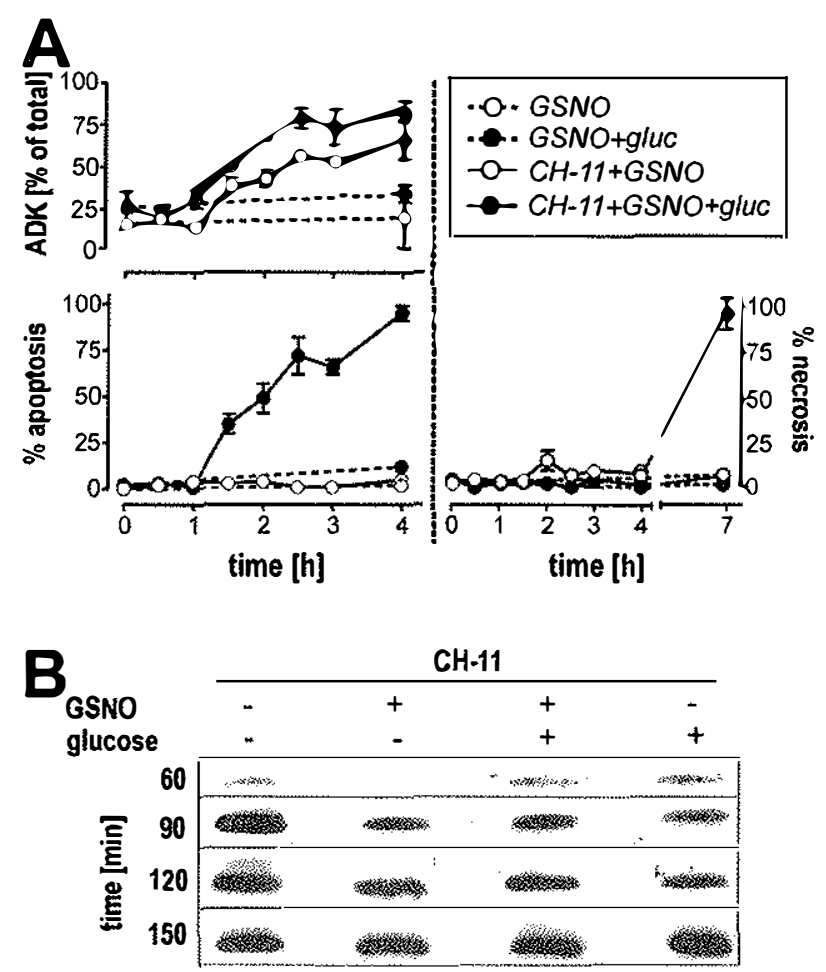

FIG. 4. Time course of apoptotic events in CH-11-treated cells exposed to NO-donors. (A) Jurkat cells were incubated in PNG medium with combinations of glucose, GSNO and $\mathrm{CH}-11(100 \mathrm{ng} / \mathrm{ml})$ as indicated. Apoptosis and necrosis were quantitated by H-33342/ SYTOX staining. Adenylate kinase activity was measured spectophotometrically in cytosolic fractions. Data are given as as $\%$ of the total enzyme activity releasable by Triton X-100. Corresponding ATP data are found in lig. 3. Data are means \pm SD from triplicate determinations. (B) Cytochrome c release was analyzed by immunoblotting cytosolic fractions of Jurkat cells after incubation with combinations of glucose, NO-donors and CH-11 for 60, 90, 120 and 150 min. Data are representative for 3 similar experiments.

direct activation of caspases-3/7 by upstream signalling caspases, independent of ATP-controlled steps [30]. Nonetheless, this small increase in caspase activity was not sufficient to promote apoptosis.

In a final set of experiments, we examined whether the lack of caspase activity after NO-driven or oligomycin-driven ATP depletion could be explained by a failure to process inactive procaspases. Different NOdonors as well as oligomycin prevented the processing

90,120 and $150 \mathrm{~min}$. For the time point $60 \mathrm{~min}$, the entire gel, including non-specific bands, is shown as a control for equal protein loading. The total releasable amount of cytochrome $c$ was determined by Triton X-100 lysis. (C) Cells were incubated as in (A) but GSNO was substituted with oligomycin $(2.5 \mu \mathrm{M}$, olig). The amount of cytochrome $\mathrm{c}$ in the cytosol was determined by densitometric analysis of the Western blot, and data are given as percentage of the total amount releasable by Triton X-100. Values are means of density readings from two Western blots. 


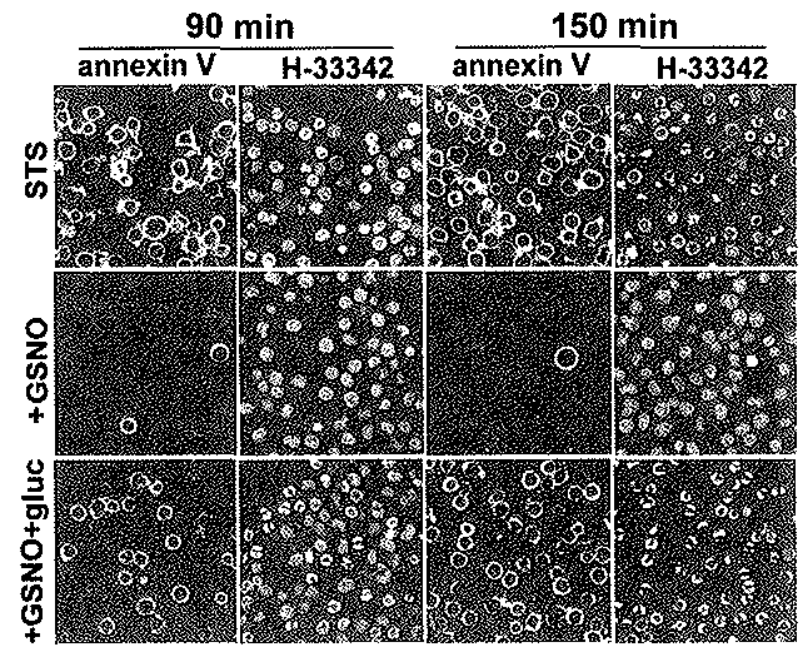

FIG. 5. Inhibition of CD95 and STS-induced phosphatidylserine translocation by NO. Juskat cells were stimulated with STS directly (STS) or after preincubation with GSNO (+GSNO), or GSNO plus glucose (GSNO $\%$ gluc). After $90 \mathrm{~min}$ and after $150 \mathrm{~min}$, cells were stained with H-33342 and fuorescent annexin V, and imaged by confocal microscopy. Cells treated with STS + GSNO did not show annexin staining before rupture of the plasma membrane (not shown). Data are representative of 6 similar independent experiments.

of procaspase- 3 and procaspase- 7 , and the cleavage of poly-(ADP-ribose) polymerase (PARP) in PNG medium. In the presence of glucose, procaspase- 3 was processed to the active form and the intracellular caspase-3 substrate PARP was cleaved accordingly (Fig. 6B).

In Jurkat cells exposed to $\mathrm{CH}-11$, caspase- 8 is activated mainly downstream of mitochondrial steps $[26,30]$. Accordingly, we found that the processing of this protease was modulated by $\mathrm{NO}$ and glucose similar to that of caspase-3 and caspase-7 (Fig. 6C).

\section{DISCUSSION}

The results presented here show that the endogenous mediator NO can potently inhibit apoptosis in cells that are primarily dependent on mitochondrial energy production (i.e. in the absence of glycolytic ATP production). In PNG medium, the NO-donors released $\mathrm{NO}$ at a rate of $0.5-1 \mu \mathrm{M} / \mathrm{min}$, and severalfold higher concentrations were needed to prevent the execution of apoptosis in the presence of glucose. The inhibition of apoptosis by NO was always linked to induction of necrosis with delayed onset. Only when experiments were terminated prematurely, cell death appeared to be entirely prevented by NO. In other experimental systems, cells may be rescued permanently by NO if the triggering insult is milder, or if the insult is removed during the lag period between block of apoptosis execution and onset of necrosis. In this context, it is

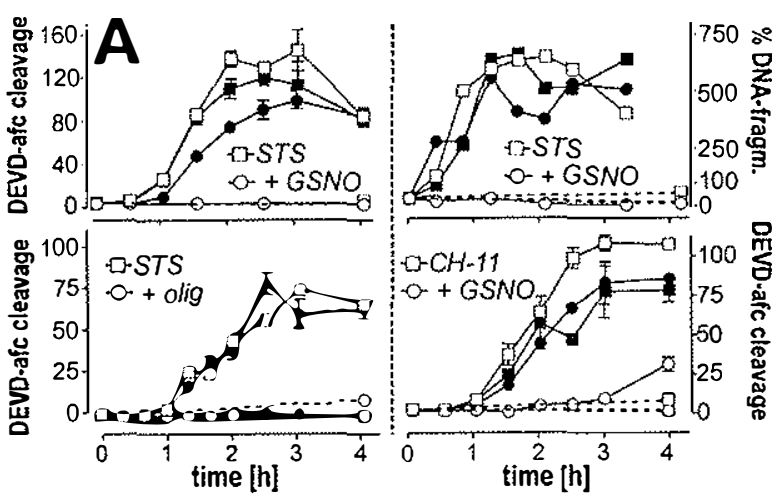

filled symbols: + glucose; dashed lines: w/O STS/CH-11
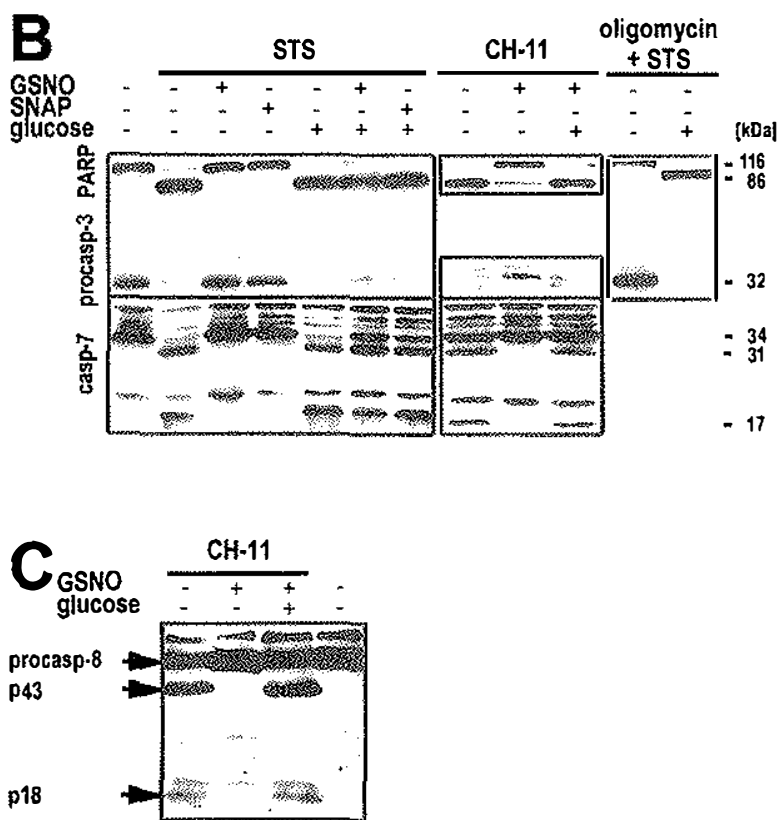

FIG. 6. Modulation of STS-induced cell death by oligomycin and glucose. (A) Jurkat cells were incubated in PNG medium with (filled symbols) or without (open symbols) glucose $(10 \mathrm{mM})$ as described in Fig. 3. Cells were treated with either STS or CH-11 alone (squares), or in the presence of either GSNO or oligomycin (circles). Incubations with NO or oligomycin in PNG medium, but omitting the apoptotic stimuli are indicated by dashed lines. Caspase activity was measured as DEVD-afc cleavage activity in pmol $x$ min $^{\prime 1}$ per $10^{6}$ cells. Data are means t SD from triplicate determinations. DNA-fragmentation was measured by ELISA and data are expressed as \% of control Data are means from duplicate determinations. (B, C) Jurkat cells were incubated in PNG medium for $150 \mathrm{~min}$ with different combinations of STS, CH-11, glucose, oligomycin and NO-donors as indicated. Intracellular proteolysis was determined by Western blot. Note that PARP and procaspase-3 were probed on the same membrane to ensure equal protein loading for procaspase-3, because the antibody used detected only the proform, but not the cleavage products. The antibody against caspase-7 detected the cleavage inter mediate at $31 \mathrm{kDa}$ and the active fragment of $17 \mathrm{kDa}$ in addition to the $34 \mathrm{kDa}$ proform. The antibody against caspase- 8 detected the $43 \mathrm{kDa}$ intermediate and the $18 \mathrm{kDa}$ active fragment in addition to the procaspase- 8 . 
important to note that NO prevented the translocation of the phagocytosis marker [1] phosphatidylserine to the outer surface of the plasma membrane. This would possibly prevent a premature phagocytosis of recovering cells protected by NO. On the other hand, this could also preclude the rapid clearance of cells later dying by necrosis. The latter condition would facilitate inflammatory reactions, and provide the basis for the aggravating role of $\mathrm{NO}$ in some chronic infiammations [8].

Earlier work has shown that NO can modulate cell death in multiple ways. In different experimental systems caspase-activation and apoptosis may be either triggered by NO [31], or entirely prevented. For instance, S-nitrosylation of active caspases has been suggested to delay TNF-triggered cytochrome c release [32], and prevent apoptotic death [19-21]. An additional mechanism whereby $\mathrm{NO}$ can affect the execution of apoptosis is NO-dependent ATP-depletion (this work and M.L.: unpublished data). The two steps affected by a lack of ATP are the timely release of cytochrome c, and, independently, the activation of execution caspases downstream of cytochrome c-release.

During apoptosis, irreversible mitochondrial alterations are marked by a release of cytochrome $c$ from the mitochondrial intermembrane space to the cytosol [29]. This would switch the mitochondria from energy production to superoxide production [33]. Therefore, a delay in cytochrome c release in ATP-depleted cells would delay the generation of detrimental reactive oxygen species and give cells the time to compensate a putatively lethal insult. The ATP-requirement of this early step may be linked to the important role of the mitochondrial ATPase [34] and the adenine nucleotide translocator [35] in early apoptotic processes. The delayed release of mitochondrial intermembrane proteins in our experimental system was unlikely to be modulated by caspase nitrosylation, since STS-triggered cytochrome $c$ and $A D K$ release are completely independent of caspase activity [24].

The finding that in ATP-depleted cells the major part of cytochrome $c$ was released from mitochondria to the cytosol without causing the activation of caspases-3/ $7 / 8$, suggests also that downstream of cytochrome $c$ release, and upstream of caspase-activation, there is a second ATP-dependent step. Most likely the formation of the apoptosome complex from procaspase-9, Apaf-1 and ATP/dATP [36] is precluded under conditions of severe ATP-depletion. Thus, active caspases which could be inhibited by S-nitrosylation are probably not formed.

The full execution of the apoptotic program beyond this step (e.g. proteolysis of nuclear substrates) was strongly inhibited by chemical ATP-depletors $[5,6,37,38]$. Here we show that the endogenous mediator NO can deplete ATP in normoxic cells, which are metabolically competent and possess a functional mitochondrial respiration. Our findings that NO can switch apoptosis to necrosis by lowering intracellular ATP may be relevant to understand pathologic situations associated with enhanced NO production, and localized high rates of necrotic cell death.

\section{ACKNOWLEDGMENTS}

We are grateful to Dr. G. Cohen for the gift of the anti-caspase-7 antibody and to Dr. K. Schulze-Osthoff for the anti-caspase-8 antibody. The perfect technical assistance of T. Schmitz and J. Peterke is gratefully acknowledged. This study was supported by grants from the University of Konstanz AFF, the Deutsche Forschungsgemeinschaft (DFG) and the EEC grants ENV4-CT96-0169, 12029-97-06 F1ED ISP D, and BMIH4CT97-2410.

\section{REFERENCES}

1. Ren, Y., and Savill, J. (1998) Cell Death Differ. 5, 563-568.

2. Wyllie, A. H., Kerr, J. F., and Currie, A. R. (1980) Int. Rev. Cytol. 68, 251-306.

3. Hirsch, T., Marchetti, P., Susin, S. A., Dallaporta, B., Zamzami, N., Marzo, I., Geuskens, M., and Kroemer, G. (1997) Oncogene 15, 1573-1581.

4. Leist, M., and Nicotera, P. (1997) Biochem. Biophys. Res. Commun. 236, 1-9.

5. Leist, M., Single, B., Castoldi, A. F., Kühnle, S., and Nicotera, P. (1997) J. Exp. Med. 185, 1481-1486.

6. Eguchi, Y., Shimizu, S., and Tsujimoto, Y. (1997) Cancer Res. 57, 1835-1840.

7. Ding, A. H., Nathan, C. F., and Stuehr, D. J. (1988) J. Immunol. 141, 2407-2412.

8. Nathan, C. (1997) J. Clin. Invest. 100, 2417-2423.

9. Bohlinger, I., Leist, M., Barsig, J., Uhlig, S., Tiegs, G., and Wendel, A. (1995) Hepatology 22, 1829-1837.

10. Beauvais, F., Michel, L., and Dubertret, L. (1995) FEBS Lett. 361, 229-232.

11. Genaro, A. M., Hortelano, S., Alvarez, A., Martínez-A, C., and Boscá, L. (1995) J. Clin. Invest. 95, 1884-1890.

12. Mannick, J. B., Asano, K., Izumi, K., Kleff, E., and Stamler, J. S. (1994) Cell 79, 1137-1146.

13. Kim, Y.M., Talanian, R. V., and Billiar, T. R. (1997) J. Biol. Chem. 272, 31138-31148.

14. Hebesteit, H., Dibbert, B., Balatti, I., Braun, D., Schapowal, A., Blaser, K., and Simon, H-U. (1998) J. Exp. Med. 187, 415-425.

15. Stadler, J., Curran, R. D., Ochoa, J. B., Harbrecht, B.G., Hoffman, R. A., Simmons, R. L., and Billiar, T. R. (1991) Arch. Surg. 126, 186-191.

16. Schweizer, M., and Richter, C. (1994) Biochem. Biophys. Res. Commun. 204, 169-175.

17. Cleeter, M. W. J., Cooper, J. M., Darley-Usmar, V. M., Moncada, S., and Schapira, A. H. V. (1994) FEBS Lett. 345, 50-54.

18. Clementi, E., Brown, G. C., Feelisch, M., and Moncada, S. (1998) Proc. Natl. Acad. Sci. USA 95, 7631-7636.

19. Dimmeler, S., Haendeler, J., Nehls, M., and Zeiher, A. M. (1997) J. Exp. Med. 185, 601-607.

20. Mohr, S., Zech, B., Lapetina, E.G., and Brüne, B. (1997) Biochem. Biophys. Res. Commun. 238, 387-391. 
21. Melino, G., Bernassola, F., Knight, R. A., Corasaniti, M. T., Nistico, G., and Finazzi-Agro, A. (1997) Nature 388, 432-433.

22. Leist, M., Volbracht, C., Kiihnle, S., Fava, E., Ferrando-May, E., and Nicotera, P. (1997c) Mol. Med. 3, 750-764.

23. Koopman, G., Reutelingsperger, C. P. M., Kuijten, G. A. M., Keehnen, R. M. J., Pals, S. T., and van Oers, M. H. J. (1994) Blood 84, 1415-1420.

24. Single, B., Leist, M., and Nicotera, P. (1998) Cell Death Differ. 5, 1001-1003.

25. MacFarlane, M., Cain, K., Sun, X. M., Alnemri, E. S., and Cohen, G. M. (1997) J. Cell Biol. 137, 469-479.

26. Ferraxi, D., Stepczynska, A., Los, M., Wesselborg, S., and Schulze-Osthoff, K. (1998) J. Exp. Med. 188, 979-984.

27. Thornberry, N. A. (1994) Meth. Enzymol. 244, 615-631.

28. Leist, M., Single, B., Künstle, G., Volbracht, C., Hentze, H., and Nicotera, P. (1997b) Biochem. Biophys. Res. Commun. 233, 518522.

29. Liu, X., Kim, C. N., Yang, J., Jemmerson, R., and Wang, X. (1996) Cell 86, 147-157.

30. Scaffidi, C., Fulda, S., Srinivasan, A., Friesen, C., Li, F., Toma- selli, K. J., Debatin, K. M., Krammer, P. H., and Peter, M. E. (1998) EMBO J. 17, 1675-1687.

31. Chlichlia, K., Peter, M. E., Rocha, M., Scaffidi, C., Bucur, M., Krammer, P. H., Schirrmacher, V., and Umansky, V. (1998). Blood 91, 4311-4320.

32. Kim, Y., Kim, T., Seou, D., Talanian, R. V., and Billiar, T. R. (1998) J. Biol. Chem. 273: 31437-31441.

33. Cai, J., and Jones, D. P. (1998) J. Biol. Chem. 273, 11401-11404.

34. Matsuyama, S., Xu, Q., Velours, J., and Reed, J. C. (1998) Mol. Cell 1, 327-336.

35. Marzo, I., Brenner, C., Zamzami, N., Jürgensmeier, J. M., Susin, S. A., Vieira, H. L. A., Prévost, M.-C., Xie, Z., Matsuyama, S., Reed, J. C., and Kroemer, G. (1998) Science 281, 2027-2031.

36. Zou, H., Henzel, W. J., Liu, X., Lutschg, A., and Wang, X. (1997) Cell 90, 405-413.

37. Schwab, B. L., Leist, M., Knippers, R., and Nicotera, P. (1998) Exp. Cell Res. 238, 415-421.

38. Göhring, F., Schwab, B. L., Nicotera, P., Leist, M., and Fackelmayer, F. O. (1997) EMBO J. 16, 7361-7371. 